\title{
THE DIALECTICS OF RESILIENCE: A Multilevel Analysis of a Telehealth Innovation
}

\author{
Sunyoung Cho \\ Lars Mathiassen \\ Daniel Robey \\ Georgia State University \\ Atlanta, GA U.S.A.
}

\begin{abstract}
Resilience is commonly portrayed as a positive capability that allows individuals and organizations to thrive in dynamic contexts. This paper questions this oversimplified view based on a dialectical analysis of a telehealth innovation. We analyze the major contradictions that characterize the adoption of the innovation. First, we analyze contradictions between individuals and groups within each adopting hospital. Second, we analyze contradictions between the adopting hospitals. This two-level analysis leads to a deeper understanding of resilience as a dialectical process. The analysis of the case shows that, although the participating individuals and organizations demonstrated apparent resilience in adopting the telehealth innovation, the innovation remained in a fragile state where it was unclear whether it would continue to diffuse, stabilize as-is, or slowly deteriorate. Hence, while organizational resilience facilitated swift and successful adoption, it also created tensions that endangered further diffusion and the long term sustainability of the telehealth innovation. We suggest that understanding the future success of the innovation would be facilitated to a large extent by a dialectical analysis of the involved contradictions.
\end{abstract}

Keywords Resilience, dialectics, telehealth innovation

\section{INTRODUCTION}

The use of information technology (IT) within healthcare is increasing because of the information-intensive nature of the industry (Anderson 1997; Dwivedi et al. 2001).

\footnotetext{
Please use the following format when citing this chapter:

Cho, Sunyoung, Mathiassen, Robey, Daniel, 2006, in International Federation for Information Processing (IFIP), Volume 206, The Transfer and Diffusion of Information Technology for Organizational Resilience, eds. B. Donnellan, Larsen T., Levine L., DeGross J. (Boston: Springer), pp. 339-357.
} 
Investments in IT within healthcare have grown rapidly and were expected to reach $\$ 23.6$ billion in 2003 , rising at a rate of 9.3 percent from the $\$ 21.6$ billion expended in 2002. This growth is not surprising and will likely accelerate given that IT infrastructure and services in healthcare are estimated to be 10 to years behind other industries such as banking, airlines, and manufacturing (Raghupathi 1997). Since the late 1990 s, telehealth innovations that include provision of health care services, clinical information, and education over distance using telecommunication technology have attracted special attention (Maheu et al. 2001).

The growing investment in IT within healthcare has led to increasing research interests in and experiments with healthcare and telehealth innovations (Chiasson and Davidson 2004). Many of these studies investigate the particular problems that are related to implementation and adoption of IT-based innovations within the healthcare industry (e.g., Aarts and Peel 1999; Berg 2001; Lorenzi and Riley 2003; Tanriverdi and Iacono 1998). Different types of explanations for implementation problems are provided, including knowledge barriers and management issues (e.g., Dwivedi et al. 2001; Tanriverdi and Iacono 1998), people and organizational issues (e.g., Aarts and Peel 1998; Berg 2001; Lorenzi and Riley 1997), social communication patterns (Davidson 2000), organizational structure and culture (Bangert and Doktor 2003), and enactments of different structures of reference by different stakeholder groups (Constantinides and Barrett 2006). These studies point to the importance of organizational processes in explaining the success and failure of telehealth innovations.

The purpose of this study is to continue this line of research by investigating the relationship between organizational resilience and adoption of telehealth innovations. According to the literature, resilience refers to the capability of individuals, groups, or organizations to adapt quickly to changes in their environments (Coutu 2002; Hamel and Valikangas 2003; Horne 1997; Horne and Orr 1998; Mallak 1998; Riolli and Savicki 2003; Starr et al. 2003). We base our analysis on an in-depth case study of a telehealth innovation adopted in a network of collaborating hospitals. The adopting organizations arguably demonstrated considerable resilience, resulting in successful implementation. However, many indicators suggest that the innovation reached a temporary and in some respects fragile acceptance, from which it might be unable to progress. To understand this outcome, we conduct a dialectical analysis (Bjerknes 1991; Israel 1979; Mathiassen 1998; Robey and Boudreau 1999; Robey et al. 2002) of the major contradictions that characterize this particular adoption initiative. We analyze contradictions at two levels of analysis: within each adopting hospital, and between the adopting organizations. This analysis is guided by the following research questions:

1. How is resilience manifest at the organizational and interorganizational levels of analysis in the adoption of a telehealth innovation?

2. How can the use of dialectics augment the analysis of resilience in the adoption of a telehealth innovation?

${ }^{1}$ News release, Sheldon I. Dorenfest \& Associates, Ltd., http://www.dorenfest.com/ pressrelease_feb2004.pdf. 
We argue that the future of the innovation depends upon the development and resolution of the involved contradictions. This analysis leads us to an understanding of the dialectics of resilience in relation to adoption of IT-based innovations in organizational contexts.

The study makes three distinct contributions. First, it contributes to research on organizational resilience (Contu 2002; Horne 1997; Hamel and Valikangas 2003; Mallak 1998; Riolli and Savicki 2003; Weick 1993) by exploring the concept in relation to organizational adoption of IT-based innovations. We suggest that resilience in relation to adoption of innovations is an elusive concept inviting interpretations from multiple and often contradictory perspectives. Specifically, we argue that contemporary definitions of resilience raise interesting issues related to the dynamics of adoption behaviors and to interactions between different levels of analysis. Second, the study adds to our knowledge of dialectics, which is already established as a useful approach to IS research (Bjerknes 1991; Mathiassen 1998; Mathiassen and Nielsen 1989; Robey and Boureau 1999; Robey and Holmstrom 2001; Robey et al. 2002; Sabherwal and Newman 2003) and to organization studies in general (Das and Teng 2000; Ford and Ford 1994; Rond and Bouchikhi 2004). Building on this tradition, we demonstrate a detailed approach to conceptualizing, identifying, and analyzing contradictions to uncover the complex dynamics involved in adoption of IT-based innovations. Finally, the study adds to our understanding of the challenges involved in adopting and managing telehealth innovations in an interorganizational context.

The argument is structured as follows. The next section presents the theoretical foundation for the study by reviewing the literature on organizational resilience and on the use of dialectics in organization studies. After a discussion of the adopted research approach we continue with a dialectical analysis of resilience in relation to adoption of the telehealth innovation under examination. Finally, we discuss the contribution of this research and its implications for both research and practice.

\section{THEORETICAL FOUNDATION}

In this section, we review the two lines of research on which this study builds and to which it contributes: the literature on organizational resilience and the literature on the use of dialectics in organization studies.

\subsection{Resilience}

Resilience research has its origin in psychology (Coutu 2002; Reinmoeller and van Baardwijk 2005). It started with pioneering studies by Norman Garmezy of different responses and attitudes of children whose parents were schizophrenic. Garmezy concluded that a quality of resilience played a role in the mental health of those children. Since then, many studies have been carried out and theories abound about characteristics of resilience (Coutu 2002). The majority of these studies are at the individual level. Horne and Orr (1998) note that the term resilience began to be applied as an organizational quality in the early 1990s. More recently, the concept of the "resilient organi- 
zation" has gained popularity as a quality that might help organizations survive and thrive in difficult or volatile environments (Riolli and Savicki 2003).

Most definitions of resilience as an organizational quality emphasize its relationship with effective adaptation. Mallak (1998) defines resilience as the ability of an individual or organization to expeditiously design and implement positive adaptive behaviors matched to the immediate situation, while enduring minimal stress. Mallak considers organizational resilience as closely related to individual employees' resilience. Hamel and Valikangas (2003) define resilience as the ability to dynamically reinvent business models and strategies as circumstances change. Starr et al. (2003) define enterprise resilience as the ability to withstand systemic discontinuities and adapt to new risk environments. Horne and Orr (1998) define resilience as "a fundamental quality of individuals, groups, organizations, and systems as a whole to respond productively to significant change that disrupts the expected pattern of events without engaging in an extended period of regressive behavior" (p. 31). In general, these definitions carry positive connotations. The underlying assumption is that resilient organizations thrive in dynamic environments.

For the sake of theoretical clarity, it would be better if the concept of resilience were decoupled from the concept of effective adaptation. Organizational resilience should be conceptually distinct from the outcomes with which it is associated. If it is not conceptually distinct, resilience becomes conflated and confounded with effective adaptation and its explanatory powers are removed. Reinmoeller and van Baardwijk (2005) offer from that point of view a more promising approach in which resilience is regarded as a process capability, instrumental in overcoming barriers to change and in developing multiple sources of competitive advantage. Three advantages to this approach seem apparent. First, resilience is related to the process of change, where specific capabilities may play roles in overcoming specific barriers to change. Second, resilience is multifaceted, not a single quality. Thus, organizations may possess some resilient capabilities and not others. Third, in a process perspective, resilience becomes a capability that may be related to both successful and unsuccessful adoption behaviors. For example, under conditions of external threat, an organization might quickly adopt an innovation without any certainty that it will be sustained in the long run. Indeed, resilient responses in the short run might neglect more fundamental organizational capabilities related to long-run performance.

The process perspective on resilience is consistent with the usage of the term in ordinary language. The Oxford Advanced Learner's Dictionary of Current English defines resilience as the "quality or property of quickly recovering the original shape or condition after being pulled, pressed, crushed, etc." (Hornby 1988). In the context of adoption of IT-based innovations, this definition allows for two different and quite opposite interpretations. On the one hand, this definition can imply that a resilient organization is able to adopt an innovation and quickly recover from the interruption and return to serving its mission. On the other hand, this definition can also imply that a resilient organization is able to absorb or reject an innovation without any significant change. The ordinary language definition is neutral, allowing quite opposite interpretations of how organizations manage innovation adoption challenges. In either case, however, the question remains: Is it in the long term interest of an organization to resiliently adopt (or abandon) the innovation in question? 
When applied to the organizational adoption of IT-based innovations, the concept of resilience remains elusive and raises two specific issues of interpretation. First, there are interesting issues related to the dynamics of adoption of innovations, as when organizations successfully implement innovations and later return to traditional practices because the innovations were not sufficiently institutionalized. In such cases, there is potential benefit to interpreting resilience over time from a process point of view. Second, there are interesting issues related to human agency in adoption practices. Resilience is not an abstract organizational capability. It needs to be interpreted as specific and complex interactions between different levels of adoption behavior including individuals, groups, and organizational units. In other words, the analysis of resilience requires researchers to address levels-of-analysis issues (Klein et al. 1994). Resilience can be a single-level or a multilevel construct depending on the research context. As many IT-based innovations are networked and distributed, their adoption is enacted through complex social networks of multiple stakeholders. There is, therefore, a need to address issues related to level of analysis when applying resilience as a theoretical lens in this particular domain.

In summary, resilience is employed in this paper as a framework for studying adoption of IT-based innovations. We tentatively accept Reinmoeller and van Baardwijk's definition of resilience as process capabilities existing at multiple levels of analysis. However, we augment this definition with a consideration of dialectics and contradictions, as discussed next.

\subsection{Dialectics}

Organizational change has been the subject of extensive research in the fields of both management (Ford and Ford 1994; Van de Ven and Poole 1995) and information systems due to IT's role in organizational change (Mathiassen 1998; Robey and Sahay 1996). Dialectics has been adopted as one approach to understand and study social phenomena in general, and it has proven particularly useful as a framework to understand issues related to social change. Dialectics has been adopted in many organizational studies (e.g., Das and Teng 2000; Ford and Ford 1994; Rond and Bouchikhi 2004) as well as in many information systems studies (e.g., Bjerknes 1991; Chae and Bloodgood 2006; Mathiassen 1998; Mathiassen and Nielsen 1989; Robey and Boudreau 1999; Robey and Holmstrom 2001; Robey et al. 2002; Sabherwal and Newman 2003).

The core concept in dialectics is contradiction, for which a variety of definitions have been applied. According to Van de Ven and Poole (1995), dialectics assumes that organizations exist in a pluralistic world of colliding events, forces, or contradictory values that compete with each other for domination and control. The organizational consequences of IT can, therefore, be explained by reference to the relative strength of opposing forces, some promoting change and others opposing change (Robey and Boudreau (1999). Other researchers build on Mao Tse Tung's more elaborate notion of contradiction to analyze social processes (Bjerknes 1991; Israel 1979; Mathiassen 1998; Mathiassen and Nielsen 1989). Contradictions in these studies are seen as totalities that consist of two opposing elements. The opposites of a contradiction have two qualities: 
the identity of and the struggle between opposing elements. The identity refers to the contradiction as a whole and explains the paradox in which opposing elements coexist. The struggle emphasizes the dynamics that drive change. In any given situation, the relationship between the two opposites is usually uneven so that one of the opposites exerts more influence. As time passes, the relationship between the opposing elements might change as a result of their mutual struggle. Also, there are typically several contradictions in any given situation, each with elements becoming more or less dominant as the situation evolves.

We see the different notions of contradictions discussed above as complementary. The main commonality underlying these understandings is their perspective that change is the outcome of contradictory forces. Put differently, the struggle between contradictions and between the opposites of each contradiction are the main forces driving change. In this study, we adopt dialectics to analyze a situation where a telehealth innovation has been adopted by multiple organizations. Following Rond and Bouchikhi (2004), our assumption is that dialectics will help reveal the contradictions involved and that this, in turn, can lead to an understanding of key forces involved in shaping the present situation and the future trajectory of the telehealth innovation.

To support a detailed analysis of relevant contradictions, we follow Bjerknes' (1991) suggestion for identifying and analyzing contradictions. This analytic process occurs in three steps: (1) define specific contradictions, (2) analyze each contradiction's identity and struggles involving the two opposing elements, and (3) synthesize by considering all contradictions involved in the situation. To identify contradictions in the situation under investigation, we combine two sources. First, Bjerknes proposes focusing on conflicts, or antagonistic contradictions, while putting less emphasis on contradictions in which potential conflicts are temporarily resolved. Second, Robey and his colleagues (Robey and Boudreau 1999; Robey et al. 2002) suggest that opposing forces may align with specific interest groups, or they can be conceived more abstractly (e.g., as cultural assumptions, institutionalized values, or organizational memory). However conceived, contradictions can be identified and analyzed between different levels of social analysis (Bacharach et al. 1996).

\section{RESEARCH METHOD}

\subsection{Research Context}

In March 2003, the department of neurology at a large university hospital (referred to as the hub hospital) in the state of Georgia in the United States launched a telehealth innovation named REACH (the Remote Evaluation for Acute Ischemic Stroke Program). This "telestroke" system allowed neurologists from the hub hospital to use telecommunication to participate in real-time stroke assessments for patients in rural hospitals. The innovation was first implemented in one rural hospital and gradually expanded to a number of hospitals, with initial technical problems being detected and resolved effectively. At the time of our study between December 2004 and February 2005, the innovation had been adopted by seven rural hospitals. Between March of 2003 and May 
of 2004 , doctors had used REACH to evaluate 75 patients and to qualify 12 of them for treatment.

The need for the REACH system was justified by the critical lack of stroke specialist expertise in most rural areas as well as in many urban areas. This contributes to a higher rate of stroke deaths in rural and under served communities (Casper et al. 2003). For the case of non-bleeding, or ischemic, stroke, a blood-clot dissolving agent called tPA (tissue Plasminogen Activator) greatly reduces chances of severe disabilities if it is administered within 3 hours from the onset of stroke symptoms. However, it is estimated that only 2 percent of stroke patients receive its benefits, partly due to a lack of on-site stroke specialists. It is essential that a stroke specialist examine each stroke patient before tPA is administered. It is far from trivial to distinguish non-bleeding from bleeding cases, and administering tPA to a bleeding case will have immediate and most likely lethal consequences. Providing the services of stroke specialists over distances can therefore significantly increase the rate of tPA use, save many lives, and reduce chances of permanent disability.

The REACH system makes the hub hospital's stroke specialists available to examine patients at distant rural hospitals around the clock. It enables these neurologists to hear and see the patients in real time. A patient admitted to one of the participating rural hospitals gets a CT (computerized tomography) scan to help pinpoint the cause and location of the stroke, while the hub hospital is notified about the incident and the oncall neurologist is connected. The patient is then moved to a room where the telestroke cart is located, and an emergency room nurse enters the patient's information and lab results into the system. The hub hospital neurologist, now connected to the rural hospital through REACH, evaluates the patient on a standardized stroke scale through video-based interactions while seeing $\mathrm{CT}$ scan results and lab data on a screen. Voice communication between the neurologist and the clinicians and patient at the rural hospital is conducted over a land-line telephone. Decisions on TPA administration and possible patient transfer are then made by the neurologist.

The implementation and operation of the REACH system were financed by the hub hospital, with each rural hospital being responsible for its CT scanner and system infrastructure, including the fast network connection. The cost of building the telestroke cart with all necessary telecommunication, data processing, and video equipment for each rural hospital was paid by the hub hospital, and technical trouble-shooting was covered by the hub hospital's dedicated systems developer.

\subsection{Case Study Design}

A case study approach was adopted to study this telehealth innovation in the social context of the hub and rural hospitals. This choice is consistent with Yin's (2003) suggestion to consider three conditions to choose a proper research method: (1) the type of research questions posed, (2) the extent of control an investigator has over actual behavioral events, and (3) the degree of focus on contemporary as opposed to historical events. First, a case study has advantages over other research methods such as surveys and experiments in answering questions of how and why. Our research questions deal with explaining how and why a teleheath innovation is influenced by organizational 
processes traced over time. Second, our control over certain variables is not of concern in this study and we have no intention or need for manipulating the involved behaviors. Finally, we are interested in a contemporary phenomenon of a telehealth innovation within a real-life context as opposed to historical events. In addition, there is broad consensus among researchers that a case study approach is particularly well suited to study the development, implementation, and use of IT-based innovations in organizational contexts (Benbasat et al. 1987; Darke et al. 1998).

The research was designed as a single case study involving multiple sites. Thus, we define the case as the network of adopting hospitals. This definition allows us to examine relationships at different levels of analysis within the network and within individual hospitals. Despite some limitations, single cases allow researchers to investigate phenomena in depth to provide a rich understanding (Walsham 1995). Data sources included complete analysis of the telestroke encounter process, systems documentation, demonstration of REACH, site visits to the hub hospital and four rural hospitals, and stakeholder interviews. We interviewed 27 individuals in five hospitals including the hub and four rural hospitals: seven doctors, five administrative staff, three technical staff, nine nurses, one radiology technician, and two entrepreneurs. All interviews were semi-structured, lasted typically between 30 and 60 minutes, and were recorded on audio tape. Most of the interviews were individual except for four group interviews with either two or four participants. We generated field notes immediately after each interview to summarize the key content and to suggest possible interpretations. Two of the authors participated in the field interviews.

Based on the interview notes and all related documents, the two field researchers developed a comprehensive list of existing and potential contradictions related to resilience in the adoption of the telehealth innovation. This process was guided by the suggestions of Bjerknes (1991) and Robey and his colleagues (Robey and Boudreau 1999; Robey et al. 2002) with focus on contradictions among different stakeholder groups. This analysis revealed ten intra-organizational and five interorganizational contradictions. These two sets of contradictions related to adoption of the telehealth innovation were then grouped into more abstract categories of contradictions through rounds of discussions among all three authors. These iterations produced a set of six categories of contradictions covering all identified contradictions of relevance to the study. The following section presents our analysis of these contradictions.

\section{RESULTS}

In this section, we analyze the resilience of the project initiator group, the adopting organizations, and the adopting network as a whole in terms of the contradictions involved.

\subsection{Resilient Adoption}

REACH was conceived by two neurologists working at the hub hospital. They were aware that the blood-clot dissolving drug, tPA, was extremely underused in rural 
areas because of a lack of stroke specialists. Their medical vision was to demonstrate the possibility of administering tPA through the use of telehealth innovations. In 2001, they launched a systems development effort sponsored by the neurology department and the hub hospital. A core team was formed consisting of four stroke specialists and a dedicated systems developer to lead and conduct the innovation effort. All team members were patent owners of REACH, and they championed the innovation by visiting, persuading, and training clinicians and medical staff in the rural hospitals. The core team was also able to garner support for the project from the CEOs of some rural hospitals within a 2-hour driving distance from the hub hospital.

The individuals in the core team were very enthusiastic about REACH, its features, and its considerable potential for providing the neurological expertise required to administer tPA treatment to remote stroke incidents. They all shared the clinical and scientific vision that REACH could save stroke patients' lives and save many from permanent brain damage. They also realized the potential of telehealth services in other clinical practices and took pride in being pioneers in providing neurological services remotely. The members of the core team reacted swiftly to new technological opportunities in their environment; they formed a vision for telehealth innovation that could effectively extend available treatment opportunities (tPA) beyond current medical practices; and they created funding and formed a project that successfully realized that vision in collaboration between the hub and rural hospitals. In this way, the core group and the involved individuals demonstrated resilient adoption behavior.

The hub hospital also demonstrated resilience by proactively adopting telehealth innovations. The vice president of the hub hospital noted in an interview that "creation of a virtual delivery system is an ultimate goal and it is a win-win strategy in competition." According to him, the hub hospital had not sufficiently exploited its highly qualified medical staff because it served a rather small population base in competition with several other large hospitals. Forming alliances with rural hospitals and clinics seemed like a viable business model and growth strategy for the hub hospital. This would allow the hub hospital to provide clinical services to rural hospitals through systems like REACH and thereby effectively increase the number of patient referrals. Hence, the hub hospital recognized opportunities and threats in the environment, searched for new business models, and financially supported innovations like REACH, evidencing its resilience.

The network of participating rural hospitals also saw new opportunities related to this particular telehealth innovation. They were in many ways enthusiastic about $\mathrm{REACH}$. According to one $\mathrm{CFO}$ at a rural hospital, about two-thirds of the rural hospitals were operating in the red and two of the four rural hospitals involved in $\mathrm{REACH}$ reported operational deficits in the previous fiscal year. It was common for regional hospitals to have severe shortages of specialists like neurologists, psychiatrists, and pediatricians. One nurse said that many rural hospitals were considered by local patrons as a "band-aid station," providing only temporary treatment. The rural hospitals saw opportunities to compensate for shortages of stroke specialists through REACH and to provide better clinical service and build their reputations through such telehealth innovations, even though they had no explicit revenue model for using the REACH system. In this sense, the rural hospitals demonstrated resilience by improving their practices and expanding their client base through adoption of the telehealth innovation. 
Given these findings and the track record of 75 evaluated patients and $12 \mathrm{tPA}$ treatments, it is fair to say that the individuals, groups, and organizations involved demonstrated the resilience required to successfully develop and adopt REACH, a radically new type of IT-based innovation that differed from previous practices both at the hub and the rural hospitals. But how sustainable was the innovation? Despite the project initiators' enthusiasm and support, the system subsequently faced problems of financing its continued expansion. The volume of usage remained low, generating problematic cost-benefit comparisons. Moreover, issues related to turning REACH into a fully institutionalized medical practice remained unresolved. To understand these issues more completely, we explored the demonstrated resilience from a process perspective by analyzing the contradictions involved in $\mathrm{REACH}$. The major contradictions identified in REACH on both the intra- and interorganizational levels are summarized in Table 1.

\subsection{Intra-Organizational Contradictions}

We identified three major contradictions related to REACH within the hub hospital and the adopting rural hospitals.

Medical versus business agenda. Provision of high quality and state-of-the-art medical services is central to any healthcare organization. At the same time, however, the organization should have a sustainable business model to maintain its long-term existence. In that sense, the medical agenda and the business agenda are mutually dependent. This intrinsic relationship between two opposites constitutes the identity of this contradiction. In this case, we found these opposing elements to be in struggle. The medical agenda had driven the development of the innovation without being aligned with the business agenda of the hub hospital. REACH was first conceived as an academic pilot project, and the initiators did not explicitly consider the system's underlying business model. Thus, the medical agenda dominated the business agenda in the early development and adoption phases. Subsequently, when the system was actually being used at multiple sites, the struggle between the two opposites emerged as a conflict. One problem was that medical services provided from the hub hospital through the system were not properly reimbursed. In fact, the central neurologists provided free services over the system without any reimbursement. Also, the hub hospital only had vague estimates of the system's impact on referrals, and the rural hospitals expressed concerns about the low reimbursement for stroke patients from Medicare and Medicaid.

Emerging versus institutionalized work practices. Adoption of IT innovations does not occur in a vacuum. Innovations are introduced into the context of existing work practices, transforming them to some degree. The newly emerging and the existing work practices constitute in this way two opposites that eventually need to be reconciled in new, institutionalized work practices for the adoption to be successful. This intrinsic relationship between old and new work practices constitutes the identity of this contradiction. The struggle between the opposites was in this case expressed as differences between emerging and existing work practices at the rural hospitals. $\mathrm{REACH}$ required extensive interdepartmental and interorganizational communication 


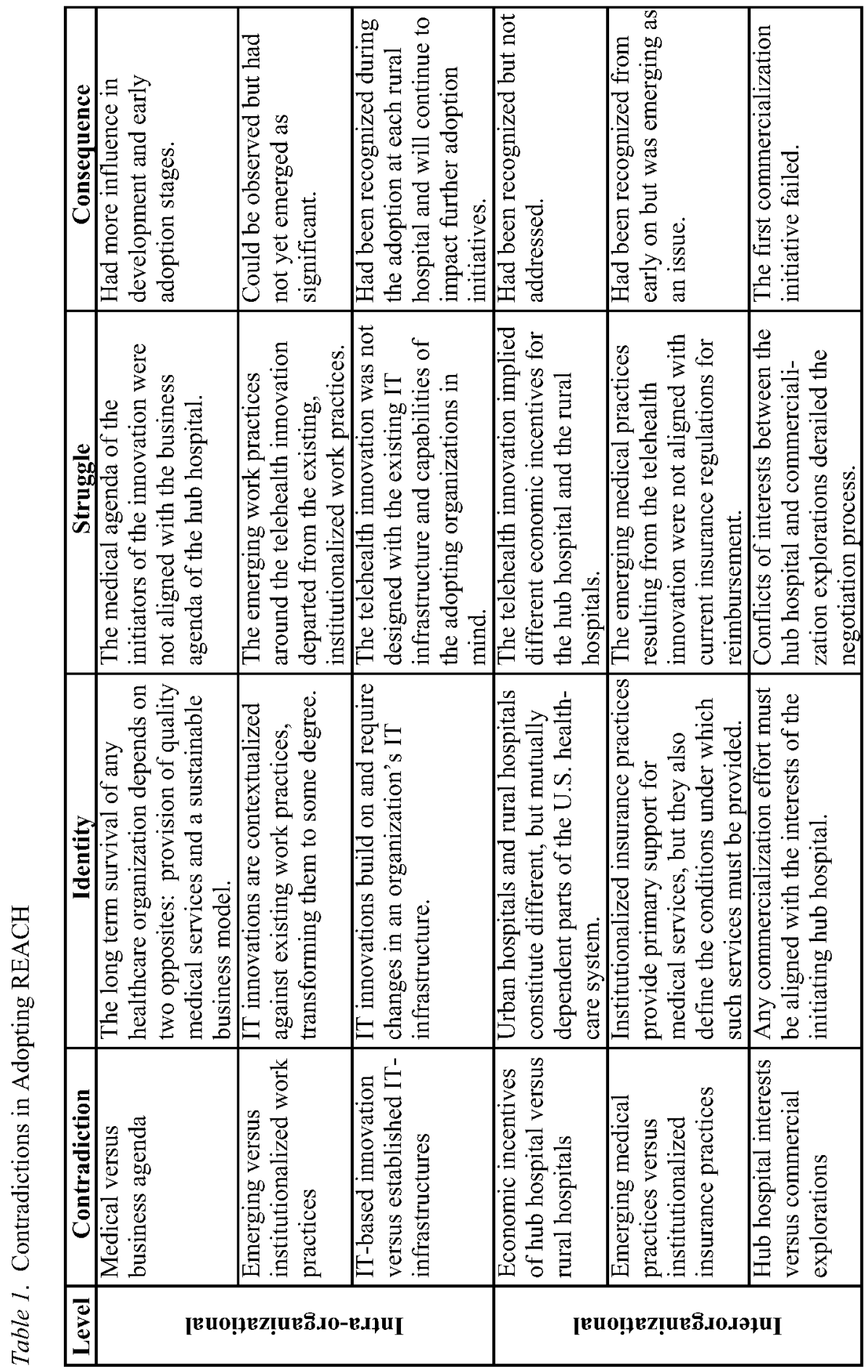


and coordination, a practice that was quite different from existing work practices in the involved rural emergency rooms (ERs). One interviewee at a rural hospital said that, before REACH, they had not experienced such intensive communication and coordination between the emergency medical service unit, the radiology department, and the ER staff. Training and education of staff was an essential mechanism to overcome the gap between old and new practices. Initial training of rural hospital staff was provided by the hub hospital, and many of the rural hospitals later conducted their own training as needed. However, the struggle was not effectively resolved. In one rural hospital the volume of system usage was extremely low, with only three cases over an 18 month period of system operation. One nurse expressed concerns about using REACH with such few encounters with the system. Overall, the struggle of the opposites had yet to become manifest as a serious conflict because of the recent adoption of REACH and the small number of adopting hospitals. The institutionalized work practices were, however, slow to change, due in part to limited use and to limited opportunities to learn new practices

IT-based innovation versus established IT-infrastructures. Like any other ITbased innovation, REACH built on and required changes in the rural hospitals' IT infrastructure. The mutual dependency between the telehealth innovation and the capabilities of the available IT infrastructures within each rural hospital constitutes the identity of this contradiction. The two opposites were in struggle as REACH was not designed with the existing IT infrastructure of the rural hospitals in mind. REACH required that certain IT capabilities and infrastructures be in place for its operation, for example, high speed Internet connections and digital CT scanners. However, some of the adopting rural hospitals lacked these capabilities. Also, most of the rural hospitals did not have full time IT employees. Those that did experienced high turnover of IT staff, making it difficult for the rural hospitals to maintain the needed IT capabilities. This struggle between the telehealth innovation and the IT infrastructure of the adopting hospitals was recognized from the early adoption stages.

\subsection{Interorganizational Contradictions}

We identified three major contradictions related to $\mathrm{REACH}$ across the adopting hospitals and the hub hospital.

Economic incentives of hub hospital versus rural hospitals. Urban hospitals and rural hospitals constitute different parts of the U.S. healthcare system. Rural hospitals serve smaller population bases and are geographically scattered around the nation, whereas urban hospitals serve larger populations with more resources and a more diverse portfolio of medical expertise. Urban hospitals support rural hospitals as well. Urban and rural hospitals are mutually dependent in that they cannot efficiently serve the entire population without each other. This interdependence between the economic incentives of the hub hospital and the rural hospitals to adopt telehealth innovations constitutes the identity of this contradiction. The introduction of REACH engaged the opposing incentives in struggle, as the innovation generated increased revenue for the hub hospital through stroke patient referrals. By the same token, REACH implied lost revenue for the rural hospitals. A CFO of one rural hospital expressed a deep concern 
of the revenue loss from using $\mathrm{REACH}$. According to the $\mathrm{CFO}$, the population base of stroke patients at many rural locations was mainly elderly and insured by Medicare and Medicaid. Because those institutions' reimbursement was below the incurred cost, rural hospitals lost money on these patients. The CFO added that the hospital would have reconsidered their adoption of the innovation if this problem had been understood in advance. Similar complaints were echoed by the other rural hospitals. This contradiction did not emerge as significant in the development and early adoption stages, since system installation and equipment were financed by the hub hospital with virtually no extra cost for the rural hospitals. However, it became an issue later as the innovation diffused.

Emerging medical practices versus institutionalized insurance practices. The U.S. healthcare system is currently sustained by insurance systems that reimburse providers of medical services. Medical practices and institutionalized insurance practices are mutually dependent and constitute an important identity in the U.S. healthcare system. These opposing elements are inherently in struggle. The emerging medical practices related to $\mathrm{REACH}$ were misaligned with insurance regulations for reimbursement. The reimbursement scheme requires telemedicine systems to be based on twoway video interaction, a requirement that $\mathrm{REACH}$ failed to meet. In addition, the neurologist on the hub side must, according to existing regulations, have a medical license in the state in which the patient incident occurs and must also be accredited by the rural hospital to participate (via telehealth services) in providing medical service for their patients. The struggle of these opposites surfaced as significant as the innovation was more frequently used.

Hub hospital interests versus commercial explorations. From the technology adoption life cycle and market development life cycle perspectives (Moore 1999, 2004), a successful innovation satisfies the interests of both the owners of the innovation and the stakeholders involved in commercialization efforts. By the same token, the interests of the hub hospital and any commercial exploration of REACH constitute an important identity in attempts to make the telehealth innovation commercially successful. Sponsored by state funds, two entrepreneurs were engaged to commercialize REACH. Rather late in the process of building a business plan for a commercial initiative, negotiations between the hub hospital and the entrepreneurs ended. The hub hospital and the involved entrepreneurs were unable to agree on a business plan that would satisfy the interests of both parties. Without explicating the details of these negotiations, the break-down was an expression of the struggle between the two opposites of this contradiction that eventually led to the failure of this attempt to radically change the underlying business proposition of the telehealth innovation.

\subsection{Relationships Between Contradictions}

In addition to the dynamics related to the struggle between the opposites within each contradiction, there are also important dynamics of interaction between contradictions in a given situation (Bjerknes 1991; Israel 1979; Mathiassen 1998). At any point in time, some contradictions may exercise more influence on the situation than others, and the relative salience of contradictions may change as the situation continues 
to unfold. We can therefore complement the analysis of individual contradictions by considering relationships between the contradictions involved in adoption of REACH. This analysis further helps us to understand the dialectics of resilience as it played out in this particular case of a telehealth adoption.

The contradiction between the medical and the business agenda dominated the adoption of REACH from its earliest development. The key stakeholders paid little attention to this contradiction as their promotion of the medical agenda shaped the initiative. The contradiction was never resolved and appeared to threaten the long-term success of REACH. This contradiction is also related to the contradiction between economic incentives of the hub hospital and the rural hospitals. While this contradiction remained latent because the hub hospital absorbed most of the costs for equipment and installation, no attempts had so far been made to develop business models that would benefit all involved hospitals. Also, the contradiction between emerging medical practices and institutionalized insurance practices surfaced as a principal contradiction both in the hub and the rural hospitals. This contradiction made hospital management more conscious of the business agenda for the telehealth innovation and led them to take a more conservative stance in financing the future of REACH. This in turn made the rural hospitals more attentive to the economic incentives for continued use of the innovation. While the contradiction between the economic incentives of the hub and the rural hospitals did not emerge as a major conflict, the business case for new rural hospitals to become involved remains weak as long as operational deficits continue and as long as the hub hospital expects the rural hospitals to share equipment and installation costs.

In the early adoption stage, the contradiction between the IT-based innovation and the established IT infrastructure emerged as a principal contradiction, as the project team had to deal with a variety of technological challenges in each adopting hospital. The impact of the contradiction was recognized by many stakeholders, but the fundamental contradiction was not resolved in time to avoid similar implementation issues as new rural hospitals became involved. The contradiction between the emerging and the institutionalized work practices and the contradiction between the hub hospital interests and commercialization explorations played minor roles in shaping the trajectory of REACH. However, there had so far not been any successful attempts to implement systematic training and education mechanisms for REACH. Also it had not so far been possible to involve new configurations of hub and rural hospitals as adopters of REACH because the contradiction between hub hospital interests and commercial exploitation remained unresolved.

\section{DISCUSSION}

We have presented a case study of the adoption of a telehealth innovation. Through the analysis above, we have shown that the initiating project group, the individual hospitals, and the entire network of adopting organizations exhibited considerable resilience in adopting the telehealth innovation. However, our analysis also shows that the telehealth innovation had arrived at a critical junction where it could either continue to be used and further diffused as a successful telehealth innovation, or it could be abandoned due to diminished financial support and sagging enthusiasm among key 
stakeholders. We argue that this crucial point in the innovation process arises because of the inherent contradictions within and across the network of adopting hospitals. The future of the innovation to a large extent depends on how these contradictions develop. From this perspective, resilience is best conceived as an ongoing process in which specific contradictions are confronted and resolved, at least temporarily. Given the interplay among multiple contradictions, each ebbing and flowing over time, resilience is not easily conceived as a general organizational quality. Rather, resilience emerges from an organization's involvement in change processes and its attempts to recognize and resolve the contradictions involved in such efforts.

Our research contributes in this way to understanding organizational resilience as an important process capability in the context of adoption of IT-based innovations. Our study suggests that levels-of-analysis issues should be addressed explicitly in considering organizational resilience. Resilience can be viewed as both a single-level and a multilevel construct depending on the research context. We agree with Klein et al. (1994) that describing the target that a researcher aims to explain has become more critical as modern organizations increasingly interact within complex business networks. When researchers deal with network-level phenomena like telehealth innovations, the levels issue should be carefully considered. As a consequence, our analysis of resilience included both the intra-organizational and interorganizational levels.

Another important consideration in understanding resilience is the notion of time. We have shown how resilience can be understood in relation to the adoption of IT-based innovations from a process point of view, and demonstrated that the resilience of an entity can change over time. In the presented case study, a network of hospitals demonstrated initially high resilience by quickly and successfully adopting a telehealth innovation that in some respects transformed current medical practices. However, the analysis also indicated that the resulting new practices were in some respects fragile and that the adopting hospitals faced emerging contradictions that would influence the future trajectory of the innovation.

Finally, we have demonstrated how the use of dialectics can augment a process perspective. The main assumption behind our analysis is that contradictions are major influences on organizational change. By analyzing the opposing elements of each contradiction, we may understand the paradoxical identity of a phenomenon as well as the dynamic struggle between opposing forces. Moreover, the analysis of the relationships between multiple contradictions allows us to appreciate the shifting requirements of technical innovation (Bjerknes 1991; Israel 1979; Mathiassen 1998). In this case, we identified six contradictions that shaped the adoption of a telehealth innovation, we analyzed the opposites involved in each contradiction, and we considered how the contradictions interacted during the adoption process. The relative importance of opposites and contradictions changed as the adoption process unfolded. In this way, we arrived at an understanding of the dialectics of resilience as it relates to adoption of this particular telehealth innovation.

This study has its limitations as well. The results section could have been substantiated with direct and detailed quotations of the interviewees. We also admit that there would be alternative perspectives to interpret resilience, for example, operational versus strategy level considerations of resilience. Within the limitations of the current study, all those issues worthy of consideration could not be covered. 


\section{CONCLUSION}

This paper has addressed two questions: (1) How is resilience manifest at the organizational and interorganizational levels of analysis in the adoption of a telehealth innovation? (2) How can the use of dialectical analysis augment the analysis of resilience in the adoption of a telehealth innovation? We argue that resilience can be a useful perspective to understand and explain key issues related to adoption of telehealth innovations and IT-based innovations in general. However, resilience needs to be understood more broadly than is currently the case in the literature. Resilience applies across levels of analysis and it changes over time in the particular context of adoption of IT-based innovations. Resilience therefore lends itself well to a dialectical perspective in which the researcher uncovers the contradictions involved and explores how contradictions shape the adoption process. This approach leads to an understanding in which resilience facilitates swift and productive adoption of IT-based innovations while at the same time implicating tensions that endanger further diffusion and the long term sustainability of the innovation.

\section{References}

Aarts, J., and Peel, V. "Using a Descriptive Model of Change When Implementing Large Scale Clinical Information Systems to Identify Priorities for Further Research," International Journal of Medical Informatics (56), 1999, pp. 43-50.

Anderson, J. G. "Clearing the Way for Physicians' Use of Clinical Information Systems," Communications of the ACM (40:8), 1997, pp. 83-90.

Bangert, D., and Doktor, R. "The Role of Organizational Culture in the Management of Clinical e-Health Systems," in Proceedings of the $36^{\text {th }}$ Annual Hawaii International Conference on System Sciences, 2003, pp. 163-171

Bacharach, S. B., Bamberger, P., and Sonnenstuhl, W. J. "The Organizational Transformation Process: The Micropolitics of Dissonance Reduction and the Alignment of Logics of Action," Administrative Science Quarterly (41:3), 1996, pp. 477-506.

Benbasat, I., Goldenstein, D. K., and Mead, M. "The Case Research Strategy in Studies of Information Systems," MIS Quarterly (11:3), 1987, pp. 369-386.

Berg, M. "Implementing Information Systems in Health Care Organizations: Myths and Challenges," International Journal of Medical Informatics (64:2-3), 2001, pp. 143-156.

Bjerknes, G. "Dialectical Reflection in Information Systems Development," Scandinavian Journal of Information Systems (3), 1991, pp. 55-77.

Casper, M. L., Barnett, E., Williams, G. I. J., Halverson, J. A., Braham, V. E., and Greenlund, K. J. "Atlas of Stroke Mortality: Racial, Ethnic, and Geographic Disparities in the United States," Centers for Disease Control and Prevention, January 2003 (available online through www.cdc.gov).

Chae, B., and Bloodgood, J. M. "The Paradoxes of Knowledge Management: An Eastern Philosophical Perspective," Information and Organization (16:1), 2006, pp. 1-26.

Chiasson, M. W., and Davidson, E. "Pushing the Contextual Envelope: Developing and Diffusing Is Theory for Health Information Systems Research," Information and Organization (14:3), 2004, pp. 155-188.

Constantinides, P., and Barrett, M. "Negotiating ICT Development and Use: The Case of a Telemedicine System in the Healthcare Region of Crete," Information and Organization (16:1), 2006, pp. 27-55. 
Coutu, D. L. "How Resilience Works," Harvard Business Review (80:5), 2002, pp. 46-55.

Darke, P., Shanks, G., and Broadbent, M. "Successfully Completing Case Study Research: Combining Rigor, Relevance and Pragmatism," Information Systems Journal (8:4), 1998, pp. 273-289.

Das, T. K., and Teng, B.-S. "Instabilities of Strategic Alliances: An Internal Tensions Perspective," Organization Science (11:1), 2000, pp. 77-101.

Davidson, E. J. "Analyzing Genre of Organizational Communication in Clinical Information Systems," Information, Technology, and People (13:3), 2000, pp. 196-209.

Dwivedi, A., Bali, R. K., James, A. E., and Naguib, R. N. G. "Telehealth Systems: Considering Knowledge Management and ICT Issues," in Proceedings of the $23^{\text {rd }}$ Annual International Conference of the IEEE, Engineering in Medicine and Biology Society, 2001, pp. 25-28.

Ford, J. D., and Ford, L. W. "Logics of Identity, Contradiction, and Attraction in Change," The Academy of Management Review (19:4), 1994, pp. 756-785.

Hamel, G., and Valikangas, L. "The Quest for Resilience," Harvard Business Review (81:9), 2003, pp. 52-63.

Hornby, A. S. Oxford Advanced Learner's Dictionary of Current English, Oxford, UK: Oxford University Press, 1988.

Horne III, J. F. "The Coming Age of Organizational Resilience," Business Forum (22:2/3/4), 1997, pp. 24-28.

Horne III, J. F., and Orr, J. E. “Assessing Behaviors That Create Resilient Organizations," Employment Relations Today (24:4), 1998, pp. 29-39.

Israel, J. The Language of Dialectics and the Dialectics of Language, Copenhagen: Munksgaard, 1979.

Klein, K. J., Dansereau, F., and Hall, R. J. "Levels Issues in Theory Development, Data Collection, and Analysis," Academy of Management Review (19:2), 1994, pp. 195-229.

Lorenzi, N. M., and Riley, R. T. "Organizational ISSUES=change," International Journal of Medical Informatics (69:2-3), 2003, pp. 197-203.

Maheu, M. M., Whitten, P., and Allen, A. E-Health, Telehealth, and Telemedicine: A Guide to Start-up and Success, San Francisco: Jossey-Bass, 2001.

Mallak, L. "Putting Organizational Resilience to Work," Industrial Management (40:6), 1998, pp. 8-13.

Mathiassen, L. "Reflective Systems Development," Scandinavian Journal of Information Systems (10:1\&2), 1998, pp. 67-118.

Mathiassen, L., and Nielsen, P. A. "Soft Systems and Hard Contradictions: Approaching the Reality of Information Systems in Organizations," Journal of Applied Systems Analysis, (16), 1989.

Moore, G. A. "Darwin and the Demon: Innovating Within Established Enterprises," Harvard Business Review (82:7\&8), 2004, pp. 86-92

Moore, G. A. Inside the Tornado: Marketing Strategies from Silicon Valley's Cutting Edge, New York: HarperBusiness, 1999.

Raghupathi, W. "Health Care Information Systems," Communications of the ACM(40:8), 1997, pp. 80-82.

Reinmoeller, P., and van Baardwijk, N. "The Link Between Diversity and Resilience," MIT Sloan Management Review (46:4), Summer 2005, pp. 61-65.

Riolli, L., and Savicki, V. "Information System Organizational Resilience," Omega: The International Journal of Management Science (31:3), 2003, pp. 227-233.

Robey, D., and Boudreau, M.-C. "Accounting for the Contradictory Organizational Consequences of Information Technology: Theoretical Directions and Methodological Implications," Information Systems Research (10:2), 1999, pp. 167-185.

Robey, D., and Holmstrom, J. "Transforming Municipal Governance in Global Context: A Case Study of the Dialectics of Social Change," Journal of Global Information Technology Management (4:4), 2001, pp. 19-31. 
Robey, D., Ross, J. W., and Boudreau, M.-C. "Learning to Implement Enterprise Systems: An Exploratory Study of the Dialectics of Change," Journal of Management Information Systems (19:1), 2002, pp. 17-46.

Robey, D., and Sahay, S. "Transforming Work Through Information Technology: A Comparative Case Study of Georgraphic Information Systems in County Government," Information Systems Research (7:1), 1996, pp. 93-110.

Rond, M. D., and Bouchikhi, H. "On the Dialectics of Strategic Alliances," Organization Science (15:1), 2004, pp. 56-69.

Sabherwal, R., and Newman, M. "Persistence and Change in System Development: A Dialectical View," Journal of Information Technology (18:2), 2003, pp. 69-92.

Starr, R., Newfrock, J., and Delurey, M. "Enterprise Resilience: Managing Risk in the Networked Economy," strategy + business, Spring 2003, pp. 1-10.

Tanriverdi, H., and Iacono, C. S. "Knowledge Barriers to Diffusion of Telemedicine," in Proceedings of the $19^{\text {th }}$ International Conference on Information Systems, R. Hirschheim, M. Newman, and J. I. DeGross (eds.), Helsinki, Finland, 1998, pp. 39-50.

Van de Ven, A. H., and Poole, M. S. "Explaining Development and Change in Organizations," Academy of Management Review (20:3), 1995, pp. 510-540.

Walsham, G. "Interpretive Case Study in IS Research. Nature and Method," European Journal of Information Systems (4), 1995, pp. 74-81.

Weick, K. E. "The Collapse of Sensemaking in Organizations: The Mann Gulch Disaster," Administrative Science Quarterly (38:4), 1993, pp. 628-652.

Yin, R. K. Case Study Research Design and Methods ( $3^{\text {rd }}$ ed.), Thousand Oaks, CA: Sage Publications, Inc., 2003.

\section{About the Authors}

Sunyoung Cho received her master's degree in computer information systems from Georgia State University in 2002 and is currently pursuing a Ph.D. at Georgia State University under the supervision of Lars Mathiassen. Sunyoung's main research area is information systems in the medical domain, especially telehealth systems. Her research interests cover adoption and diffusion factors and processes of IT-based innovations in the healtheare domain. Her current research is oriented toward a process perspective with research points of views from not only technological and organizational levels but also network and social levels. She can be reached by e-mail at sunyoung.cho@ceprin.gsu.edu.

Lars Mathiassen received his master's degree in computer science from Aarhus University, Denmark, in 1975, his Ph.D. in informatics from Oslo University, Norway, in 1981, and his Dr. Techn. degree in software engineering from Aalborg University, 1998. He is currently a professor of computer information systems at Georgia State University. His research interests are within information systems and software engineering with a particular emphasis on process innovation. He is a member of IEEE, ACM, and AIS, and coauthor of Computers in Context (Blackwell 1993), Object Oriented Analysis \& Design (Marko Publishing, 2000), and Improving Software Organizations (Addison-Wesley, 2002). Lars can be contacted at the Center for Process Innovation, J. Mack Robinson College of Business, Georgia State University, PO Box 5029, Atlanta, GA 30302-5029, or by e-mail at lmathiassen@gsu.edu.

Daniel Robey is Professor and John B. Zellars Chair of Information Systems at Georgia State University, holding a joint appointment in the Departments of Computer Information Systems and Management. He teaches courses on qualitative research methods in information systems and information technology and organizational transformation. He earned his doctorate in Administrative Science in 1973 from Kent State University. Dan is editor-in-chief of Information and Organization and serves on the editorial boards of Organization Science, 
Academy of Management Review, Information Technology \& People, and the John Wiley series on Information Systems. Dan is the author of three books and numerous articles in such journals as Management Science, Organization Science, Information Systems Research, MIS Quarterly, Human Relations, Journal of Management Information Systems, ACMTransactions on Information Systems, Information Systems Journal, Academy of Management Review, Academy of Management Journal, Information Technology \& People, and Decision Sciences. His current research includes empirical examinations of the effects of a wide range of technologies on organizational structure and patterns of work. It also includes the development of theoretical approaches to explaining the development and consequences of information technology in organizations. He can be reached by e-mail at drobey@gsu.edu. 